\title{
ANALISIS STRATEGI PENERIMAAN PAJAK BUMI DAN BANGUNAN PEDESAAN DAN PERKOTAAN (PBB P2) SERTA EFEKTIVITAS PENERIMAANNYA DI PEMERINTAH KABUPATEN MINAHASA SELATAN TAHUN 2016-2017
}

\author{
Vernando Viki Tambingon ${ }^{1}$, Hendrik Manossoh², Novi S. Budiarso ${ }^{3}$ \\ 1,2,3 Jurusan Akuntansi, Fakultas Ekonomi dan Bisnis, Universitas Sam Ratulangi, Jl. Kampus Bahu, Manado, \\ 95115, Indonesia \\ Email : viki.tambingon@gmail.com
}

\begin{abstract}
Based on Law Number 28 of 2009 states that the Land and Building Tax for Rural and Urban Areas is a tax that is controlled by the regional governmentThe purpose of this study was to determine the implementation of the strategy, measure the level of $P B B-P 2$ and countries in South Minahasa Regency in PBB P2 collection. The type of research used is descriptive qualitative data where the primary data to be used will then be analyzed, namely data that can be used for the main purpose of this study.The results of the study indicate that the strategy in UN PBB P2 collection was well implemented, although there were some obstacles in the UN collection process P2. Whereas the acceptance of PBB in P2 in 2016 and 2017 is classified as less effective.
\end{abstract}

Keywords: rural and urban property taxes revenue, strategy, effectiveness

\section{PENDAHULUAN}

Pembangunan adalah usaha yang dilaksanakan secara terencana untuk membuat perubahan yang mempunyai tujuan dalam rangka memperbaiki dan meningkatka taraf hidup, kesejahteraan, dan kualitas manusia. Pajak Bumi dan Bangunan (PBB) merupakan Pajak Negara yang dikenakan terhadap bumi dan atau bangunan berdasarkan Undang-undang nomor 12 Tahun 1985 tentang Pajak Bumi dan Bangunan sebagaimana telah diubah dengan Undang- Undang nomor 12 Tahun 1994. Pajak Bumi dan Bangunan pada awalnya adalah pajak pusat yang kemudian dialihkan menjadi pajak daerah dengan dikeluarkannya Undangundang No 28 Tahun 2009 tentang pajak daerah dan retribusi daerah. Dengan peraturan tersebut mempunyai kewenangan untuk mengelolah rumah tanggannya sendiri. Salah satunya adalah Pajak Bumi dan Bangunan yang kemudian berubah menjadi Pajak Bumi dan Bangunan Pedesaan dan Perkotaan.

Pemerinntah daerah saat ini sedang menghadapi lemahnya pendapatan daerah, dalam membiayai pengeluaran-pengeluaran di daerah, perlu adanya yang namanya pendapatan daerah. Karena dari pada itu pemerintah daerah sedang mengupayahkan peningkatan pendapatan daerah. Dalam upayah yang dilakukan pemerintah daerah pasti perlukan yang namanya strategi dalam mencapai tujuan yang telah ditetapkan pemerintah. Dalam hal ini akan dilihat bagaimana mekanisme penerimaan Pajak Bumi dan Bangunan Pedesaan dan Perkotaan, efektivitas penerimaannya beserata kendala yang dialami oleh pemerintah dalam pelaksanaan penerimaan Pajak Bumi dan Bangunan Pedesaan dan Perkotaan.

\section{TINJAUAN PUSTAKA}

Pengertian Pajak. Definisi pajak menurut Undang-Undang Nomor 16 tahun 2009 tentang Ketentuan Umum dan Tata Cara perpajakan pada pasal 1 ayat 1 yang di kutip dalam Jurnal Riset Akuntansi Going Concern Pudihang, Morasa dan Gamaliel (2017:273) menyebutkan bahwa: "Pajak adalah kontribusi wajib kepada negara yang terutang oleh orang 
pribadi atau badan yang bersifat memaksa berdasarkan Undang-Undang, dengan tidak mendapatkan imbalan secara langsung dan digunakan untuk keperluan negara bagi sebesarbesarnya kemakmuran rakyat."

\section{Pajak Daerah}

Pengertian Pajak Daerah. Menurut Undang-Undang Nomor 28 Tahun 2009, Pajak Daerah, yang selanjutnya disebut Pajak, adalah kontribusi wajib kepada Daerah yang terutang oleh orang pribadi atau badan yang bersifat memaksa berdasarkan Undang-Undang, dengan tidak mendapatkan imbalan secara langsung dan digunakan untuk keperluan daerah bagi sebesarbesarnya kemakmuran rakyat.

\section{Pajak Bumi dan Bangunan Pedesaan dan Perkotaan}

Definisi. Menurut Mardiasmo (2018:389), Pajak Bumi dan Bangunan Pedesaan dan Perkotaan adalah pajak yang di kenakan pada bumi dan /atau bangunan dimanfaatkan yang dikuasai dan/atau yang dimiliki oleh orang Badan atau pribadi, kecuali kawasan yang digunakan untuk kegiatan perhutanan, perkebunan, dan pertambangan. Sesuai kepada sektor usaha perhutanan, perkebunan, dan pertambangan. Sedangkan untuk sektor usaha perkebunan, perhutanan, pertambangan, dan usaha tertentu lainnya masih dipungut oleh pemerintah pusat.

Strategi. Menurut David (2011:18), Strategi merupakan alat yang bertujuan jangka panjang yang harus diraih. Strategi bisnis mencakup diversifikasi, ekspansi georafis, pengembangan produk, akusisi, penetrasi pasar dan usaha patungan atau joint venture.Strategi merupakan kegiatan potensial yang memerlukan keputusan manajemen puncak dan sumber daya perusahaan jumlah besar. Jadi strategi merupaka sebuah tindakan kegiatan atau aksi yang dilakukan oleh perusaan atau seseorang untuk mencapai tujuan yang telah ditetapkan atau sasaran.

Efektivitas. Menurut Mahmudi (2010 : 143). "Efektivitas adalah hubungan antara output dengan tujuan. Semakin besar kontribusi output terhadap pencapaian tujuan, maka semakin efektif organisasi, program dan kegiatan. Jika ekonomi berfokus pada input dan efisiensi pada output atau proses, maka efektivitas berfokus pada outcome (hasil). Suatu organisasi, program atau kegiatan dinilai efektif apabila output yang dihasilkan bias memenuhi tujuan yang diharapkan.

\section{METODE PENELITIAN}

Jenis Penelitian. Penelitian ini merupakan penelitian kualitatif deskriptif

Tempat Penelitian. Tempat penelitian ini dilakukan di Kantor Badan Pengelola Pajak dan Retribusi Daerah Kabupaten Minahasa Selatan, Jln. Trans Sulawesi, Pondang, Amurang Timur, Kabupaten Minahasa Selatan.

Waktu Penelitian. Jangka waktu penyusunan penelitian ini mulai dari Agustus 2018 sampai dengan selesai.

Jenis Data. Dalam penelitian ini, peneliti menggunakan jenis data kualitatif dan data kuantitatif.

1. Data kualitatif. Data yang dibutuhkan dalam penelitian ini adalah strategi pemungutan PBB P2 dan kendala yang dialami selama pemungutan PBB P2 yang dikumpulkan dengan metode wawancara. Dan dokumentasi berupa gambaran umum berdirinya BP2RD Kabupaten Minahasa Selatan, struktur organisasi dan pembagian tugas-tugas dalam pelaksanaan pemungutan PBB P2. Penelitian ini untuk menggambarkan secara umum faktor penghambat pemungutan PBB P2 dan tingkat efektivitas penerimaan PBB P2.

2. Data kuantitatif. Data yang diperlukan dalam penelitian ini adalah data penerimaan pajak PBB P2 selama 2 tahun berjalan (2016-2017), yang diperoleh melalui Badan Pengelola 
Pajak dan Retribusi Daerah dan Data tentang target yang pencapaian penerimaan PBB P2 selama 2 tahun berjalan (2016-2017).

Sumber Data. Dalam penelitian ini, peneliti akan menggunakan sumber data primer. Sumber data primer yang akan dikumpulkan oleh peneliti yaitu dengan cara melakukan wawancara secara langsung kepada pegawai pajak Kabupaten Minahasa Selatan dan pengumpulan dokumen-dokumen yang berkaitan dengan pemungutan pajak pada Kabupaten Minahasa Selatan.

Metode Pengumpulan Data. Metode pengumpulan data yang digunakan dalam penelitian ini :

1. Teknik Wawancara. Pada tahap wawancara ini, peneliti akan mengajukan pertanyaanpertanyaan kepada Pimpinan Badan Pengelola Pajak dan Retribusi Daerah Kabupaten Minahasa Selatan. Yang diuraikan sebagai berikut : (a) Bagaimana sejerah berdirinya BP2RD Kabupaten Minahasa Selatan?; (b) Bagaimana mekanisme strategi yang dilakukan dalam pemungutan PBB P2 ?; dan (c) Apa saja kendala yang dialami pemerintah Kabupaten Minahasa Selatan dalam pelaksanaan pemungutan PBB P2 ?

2. Dokumentasi. Dalam penelitian ini peneliti membutuhkan dokumentasi yaitu dengan cara mengumpulkan dokumen-dokumen yang berhubungan dengan pemungutan dan target dari penerimaan Pajak Bumi dan Bangunan Pedesaan dan Perkotaan yang akan diteliti melalui Badan Pengelola Pajak dan Retribusi Daerah Kabupaten Minahasa Selatan.

Metode dan proses analisis data. Metode analisis data yang digunakan dalam penelitian ini adalah metode analisis kualitatif deskriptif. Tahapan-tahapan analisis data dalam penelitian ini sesuai dengan analisis kualitatif deskriptif dalam menganalisis data yang berkaitan dengan PBB P2 pada Badan Pengelola Pajak dan Retribusi Daerah yaitu sebagai berikut:

1. Pengumpulan data. Dalam hal ini peneliti akan mengumpulkan data-data yang berkaitan dengan strategi yang digunakan untuk mengoptimalkan penerimaan PBB P2 lewat wawancara dengan pihak BP2RD Kabupaten Minahasa Selatan, serta apa saja kendala yang dialami dalam pemungutan PBB P2 dan dokumen - dokumen yang menyajikan tentang penerimaan PBB P2 pada tahun 2016-2017.

2. Analisis data. Data yang akan di analisis adalah sebagai berikut:

a. Analisis strategi. Data yang telah di dapatkan berupa strategi penerimaan PBB P2 yang kemudian akan di analisis realisasi strateginya dengan melihat tingkat pencapaian target penerimaan PBB P2.

b. Analisis Efektivitas. Data yang berupa dokumen-dokumen tentang perealisasian anggaran penerimaan PBB P2 akan dihitung menggunakan rasio efektivitas keuangan daerah sesuai dengan rumus sebagai berikut.

$$
\text { Efektivitas }=\frac{\text { Realisasi Penerimaan Pajak }}{\text { Target Penerimaan Pajak }} \times 100 \%
$$

3. Pengambilan keputusan. Dalam hal ini berdasarkan hasil analisis dan wawancara diambil penarikan kesimpulan. Penarikan kesimpulan dilakukan dengan keputusan didasarkan pada pengambilan data, dan penyajian data yang merupakan jawaban atas masalah yang diangkat dalam penelitian.

\section{HASIL PENELITIAN DAN PEMBAHASAN}

\subsection{Hasil Penelitian}

Penelitian ini dilakukan pada data BP2RD Kabupaten Minahasa Selatan untuk mengetahui strategi yang diterapkan terkait pemungutan PBB P2, efektivitas penerimaan PBB P2 pada tahun 2016-2017, dan kendal-kendala yang dialami dalam pemungutan PBB 
P2. Data yang dibutuhkan dalam penelitian ini adalah data realisasi penerimaan pajak khususnya pada sektor PBB P2.

Tabel 1. Profil / Identitas Narasumber

Nama Narasumber Identitas Narasumber

Jans Waraba, SPd

Bani S. P. Zega, SS

Sumber : Data Primer (diolah 2018)

Analisis Strategi. Berdasarkan wawancara yang dilakukan dengan BP2RD Kabupaten Minahasa Selatan tentang strategi penerimaan PBB. Bapak Bani S. P. Zega, SS menyatakan bahwa: "Strategi dalam pemungutan PBB tahap awalnya adalah dengan menentukan sistem yang akan digunakan dalam pemungutan PBB, untuk pelaksaannya yaitu dengan implementasi secara teknis di lapangan dan untuk penilaian sendiri, dilihat dari tingkat penerimaan $P B B$.”

\section{Analisis Efektivitas}

Tabel 2. Target dan Perealisasian PBB-P2 Kabupaten Minahasa Selatan

Tahun Anggaran 2016-2017

\begin{tabular}{|c|c|c|c|c|c|}
\hline \multirow{3}{*}{ No. } & \multirow[b]{3}{*}{ Kecamatan } & \multirow{2}{*}{\multicolumn{2}{|c|}{2016}} & \multirow{2}{*}{\multicolumn{2}{|c|}{2016}} \\
\hline & & & & & \\
\hline & & Penetapan (Rp) & $\begin{array}{l}\text { Realisasi } \\
\text { (Rp) }\end{array}$ & Penetapan (Rp) & $\begin{array}{l}\text { Realisasi } \\
\text { (Rp) }\end{array}$ \\
\hline 1 & Modoinding & 114.263 .344 & 97.680 .041 & 113.323 .983 & 108.217 .387 \\
\hline 2 & Maesaan & 111.567 .978 & 101.259 .410 & 106.777 .788 & 96.399 .657 \\
\hline 3 & Tompaso Baru & 111.052 .080 & 109.834 .890 & 110.767 .929 & 109.201 .376 \\
\hline 4 & Ranoiapo & 122.136 .730 & 110.735 .599 & 121.354 .295 & 117.859 .555 \\
\hline 5 & Motoling & 75.427 .080 & 67.522 .864 & 75.873 .594 & 57.608 .969 \\
\hline 6 & Motoling Barat & 107.279 .736 & 94.159 .997 & 105.577 .412 & 102.353 .799 \\
\hline 7 & Motoling Timur & 96.778 .104 & 95.337 .104 & 96.709 .971 & 96.709 .971 \\
\hline 8 & Kumelembuai & 79.101 .532 & 75.704 .694 & 90.324 .879 & 90.285 .379 \\
\hline 9 & Sinonsayang & 81.299 .079 & 73.430 .292 & 102.701 .981 & 90.235 .207 \\
\hline 10 & Tenga & 277.111.119 & 195.785 .450 & 284.444 .870 & 244.554 .897 \\
\hline 11 & Amurang Barat & 265.670 .200 & 170.505 .575 & 281.268 .818 & 162.208 .512 \\
\hline 12 & Amurang & 261.127 .065 & 153.976 .412 & 288.343 .136 & 166.727 .947 \\
\hline 13 & Amurang Timur & 232.581 .896 & 147.705 .838 & 340.288 .505 & 176.018 .887 \\
\hline 14 & Tareran & 117.518 .924 & 115.549 .105 & 125.620 .981 & 119.428 .241 \\
\hline 15 & Suluun Tareran & 67.247 .336 & 67.173 .136 & 70.680 .985 & 70.680 .985 \\
\hline 16 & Tatapaan & 129.803 .806 & 117.698 .447 & 141.176 .638 & 123.281 .082 \\
\hline 17 & Tumpaan & 203.611.998 & 166.730 .430 & 253.457 .074 & 212.534 .400 \\
\hline \multicolumn{2}{|c|}{ JUMLAH } & 2.453.578.007 & 1.960 .789 .284 & 2.708.692.839 & 2.144.306.251 \\
\hline
\end{tabular}

Sumber: Data Primer dari BP2RD Kabupaten Minahasa Selatan

Berikut adalah perhitungan tingkat efektivitas penerimaan PBB P2 di Kabupaten Minahasa Selatan pada tahun anggaran 2016 dan 2017:

Tahun 2016

$$
\text { Efektivitas }=\frac{\text { Rp. } 1.960 .789 .284}{\text { Rp. } 2.453 .578 .007} \times 100 \%=79.92 \%
$$

Berdasarkan hasil perhitungan efektivitas di atas didapatkan hasil bawah, tingkat efektivitas penerimaan PBB P2 pada Tahun 2016 di Kabupaten Minahasa Selatan adalah sebesar $79.92 \%$. 
Tahun 2017

$$
\text { Efektivitas }=\frac{\text { Rp. } 2 \cdot 144.360 .251}{\text { Rp. } 2.708 .692 .839} \times 100 \%=79.16 \%
$$

Berdasarkan hasil perhitungan efektivitas di atas didapatkan hasil bawah, tingkat efektivitas penerimaan PBB P2 pada Tahun 2016 di Kabupaten Minahasa Selatan adalah sebesar 79.16\%. Dari hasil perhitungan data di atas, didapatkan data kriteria efektivitas Pajak Bumi dan Bangunan Pedesaan dan Perkotaan di Kabupaten Minahasa Selatan pada tahun anggaran 2016-2017 sebagai berikut:

Tabel 3. Efektivitas PBB-P2 Kabupaten Minahasa Selatan

\begin{tabular}{lllll}
\hline No. & $\begin{array}{l}\text { Tahun } \\
\text { Anggaran }\end{array}$ & $\begin{array}{l}\text { Target } \\
\text { ( Rupiah })\end{array}$ & $\begin{array}{l}\text { Realisasi } \\
\text { ( Rupiah ) }\end{array}$ & $\begin{array}{l}\text { Tingkat } \\
\text { Efektivitas }\end{array}$ \\
\hline 1 & 2016 & 2.453 .578 .007 & 1.960 .789 .284 & Kurang Efektif \\
2 & 2017 & 2.708 .692 .839 & 2.144 .360 .251 & Kurang Efektif \\
\hline
\end{tabular}

Sumber: Data Olahan 2018

Adapun data perhitungan tingkat efektivitas penerimaan Pajak Bumi dan Bangunan Pedesaan dan Perkotaan berdasarkan tiap-tiap kecamatan yang ada pada Kabupaten Minahasa Selatan adalah sebagai berikut:

Tabel 4. Efektivitas PBB-P2 Skala Kecamatan Pada Kabupaten Minahasa Selatan Tahun Anggaran 2016

\begin{tabular}{|c|c|c|c|c|c|c|c|}
\hline \multirow{2}{*}{ No. } & \multirow{2}{*}{ Kecamatan } & \multicolumn{6}{|c|}{2016} \\
\hline & & \multicolumn{2}{|c|}{ Penetapan } & \multicolumn{2}{|c|}{ Realisasi } & $\%$ & Kriteria \\
\hline 1 & Modoinding & $\mathrm{Rp}$ & 114.263 .344 & $\mathrm{Rp}$ & 97.680 .041 & $85.49 \%$ & Cukup Efektif \\
\hline 2 & Maesaan & $\mathrm{Rp}$ & 111.567 .978 & $\mathrm{Rp}$ & 101.259 .410 & $90.76 \%$ & Efektif \\
\hline 3 & Tompaso Baru & $\mathrm{Rp}$ & 111.052 .080 & $\mathrm{Rp}$ & 109.834 .890 & $98.90 \%$ & Efektif \\
\hline 4 & Ranoiapo & $\mathrm{Rp}$ & 122.136 .730 & $\mathrm{Rp}$ & 110.735 .599 & $90.67 \%$ & Efektif \\
\hline 5 & Motoling & $\mathrm{Rp}$ & 75.427 .080 & $\mathrm{Rp}$ & 67.522 .864 & $89.52 \%$ & Cukup Efektif \\
\hline 6 & Motoling Barat & $\mathrm{Rp}$ & 107.279 .736 & $\mathrm{Rp}$ & 94.159 .997 & $87.77 \%$ & Cukup Efektif \\
\hline 7 & Motoling Timur & $\mathrm{Rp}$ & 96.778 .104 & $\mathrm{Rp}$ & 95.337 .104 & $98.51 \%$ & Efektif \\
\hline 8 & Kumelembuai & $\mathrm{Rp}$ & 79.101 .532 & $\mathrm{Rp}$ & 75.704 .694 & $95.71 \%$ & Efektif \\
\hline 9 & Sinonsayang & $\mathrm{Rp}$ & 81.299 .079 & $\mathrm{Rp}$ & 73.430 .292 & $90.32 \%$ & Efektif \\
\hline 10 & Tenga & $\mathrm{Rp}$ & 277.111 .119 & $\mathrm{Rp}$ & 195.785 .450 & $70.65 \%$ & Cukup Efektif \\
\hline 11 & Amurang Barat & $\mathrm{Rp}$ & 265.670 .200 & $\mathrm{Rp}$ & 170.505 .575 & $64.18 \%$ & Kurang Efektif \\
\hline 12 & Amurang & $\mathrm{Rp}$ & 261.127 .065 & $\mathrm{Rp}$ & 153.976 .412 & $58.97 \%$ & Tidak Efektif \\
\hline 13 & Amurang Timur & $\mathrm{Rp}$ & 232.581 .896 & $\mathrm{Rp}$ & 147.705 .838 & $63.51 \%$ & Kurang Efektif \\
\hline 14 & Tareran & $\mathrm{Rp}$ & 117.518 .924 & $\mathrm{Rp}$ & 115.549 .105 & $98.32 \%$ & Efektif \\
\hline 15 & Suluun Tareran & $\mathrm{Rp}$ & 67.247 .336 & $\mathrm{Rp}$ & 67.173 .136 & $99.89 \%$ & Efektif \\
\hline 16 & Tatapaan & $\mathrm{Rp}$ & 129.803 .806 & $\mathrm{Rp}$ & 117.698 .447 & $90.67 \%$ & Efektif \\
\hline 17 & Tumpaan & $\mathrm{Rp}$ & 203.611 .998 & $\mathrm{Rp}$ & 166.730 .430 & $81.89 \%$ & Cukup Efektif \\
\hline JUMLAH & & $\mathbf{R p}$ & 2.453.578.007 & $\mathbf{R p}$ & 1.960 .789 .284 & $79.92 \%$ & Cukup Efektif \\
\hline
\end{tabular}

Berdasarkan tabel data hasil perhitungan PBB Pedesaan dan Perkotaan dalam skala kecamatan pada tahun 2016 di atas, dapat dilihat bahwa terapat sembilan kecamatan di Kabupaten Minahasa Selatan yang mencapai kriteria efektif, lima kecamatan dengan kriteria cukup efektif, dua kecamatan dengan kriteria kurang efektif dan satu kecamatan dengan kriteria tidak efektif. 
Tabel 5. Efektivitas PBB-P2 Skala Kecamatan Pada Kabupaten Minahasa Selatan Tahun Anggaran 2017

\begin{tabular}{|c|c|c|c|c|c|c|c|}
\hline \multirow{2}{*}{ No. } & \multirow{2}{*}{ Kecamatan } & \multicolumn{6}{|c|}{2017} \\
\hline & & \multicolumn{2}{|c|}{ Penetapan } & \multicolumn{2}{|c|}{ Realisasi } & $\%$ & \multirow{2}{*}{$\begin{array}{l}\text { Kriteria } \\
\text { Efektif }\end{array}$} \\
\hline 1 & Modoinding & $\mathrm{Rp}$ & 113.323 .983 & $\mathrm{Rp}$ & 108.217 .387 & $95.49 \%$ & \\
\hline 2 & Maesaan & $\mathrm{Rp}$ & 106.777 .788 & $\mathrm{Rp}$ & 96.399 .657 & $90.28 \%$ & Efektif \\
\hline 3 & Tompaso Baru & $\mathrm{Rp}$ & 110.767 .929 & $\mathrm{Rp}$ & 109.201 .376 & $98.59 \%$ & Efektif \\
\hline 4 & Ranoiapo & $\mathrm{Rp}$ & 121.354 .295 & $\mathrm{Rp}$ & 117.859 .555 & $97.12 \%$ & Efektif \\
\hline 5 & Motoling & $\mathrm{Rp}$ & 75.873 .594 & $\mathrm{Rp}$ & 57.608 .969 & $75.93 \%$ & Kurang Efektif \\
\hline 6 & Motoling Barat & $\mathrm{Rp}$ & 105.577 .412 & $\mathrm{Rp}$ & 102.353 .799 & $96.95 \%$ & Efektif \\
\hline 7 & Motoling Timur & $\mathrm{Rp}$ & 96.709 .971 & $\mathrm{Rp}$ & 96.709 .971 & $100.00 \%$ & Efektif \\
\hline 8 & Kumelembuai & $\mathrm{Rp}$ & 90.324 .879 & $\mathrm{Rp}$ & 90.285 .379 & $99.96 \%$ & Efektif \\
\hline 9 & Sinonsayang & $\mathrm{Rp}$ & 102.701 .981 & $\mathrm{Rp}$ & 90.235 .207 & $87.86 \%$ & Cukup Efektif \\
\hline 10 & Tenga & $\mathrm{Rp}$ & 284.444 .870 & $\mathrm{Rp}$ & 244.554 .897 & $85.98 \%$ & Cukup Efektif \\
\hline 11 & Amurang Barat & $\mathrm{Rp}$ & 281.268 .818 & $\mathrm{Rp}$ & 162.208 .512 & $57.67 \%$ & Tidak Efektif \\
\hline 12 & Amurang & $\mathrm{Rp}$ & 288.343 .136 & $\mathrm{Rp}$ & 166.727 .947 & $57.82 \%$ & Tidak Efektif \\
\hline 13 & Amurang Timur & $\mathrm{Rp}$ & 340.288 .505 & $\mathrm{Rp}$ & 176.018 .887 & $51.73 \%$ & Tidak Efektif \\
\hline 14 & Tareran & $\mathrm{Rp}$ & 125.620 .981 & $\mathrm{Rp}$ & 119.428.241 & $95.07 \%$ & Efektif \\
\hline 15 & Suluun Tareran & $\mathrm{Rp}$ & 70.680 .985 & $\mathrm{Rp}$ & 70.680 .985 & $100.00 \%$ & Efektif \\
\hline 16 & Tatapaan & $\mathrm{Rp}$ & 141.176 .638 & $\mathrm{Rp}$ & 123.281.082 & $87.32 \%$ & Cukup Efektif \\
\hline 17 & Tumpaan & $\mathrm{Rp}$ & 253.457 .074 & $\mathrm{Rp}$ & 212.534 .400 & $83.85 \%$ & Cukup Efektif \\
\hline \multicolumn{2}{|c|}{ JUMLAH } & $\mathbf{R p}$ & 2.708.692.839 & $\mathbf{R p}$ & 2.144.306.251 & $79.16 \%$ & Cukup Efektif \\
\hline
\end{tabular}

Berdasarkan tabel data hasil perhitungan PBB Pedesaan dan Perkotaan dalam skala kecamatan pada tahun 2016 di atas, dapat dilihat bahwa terapat sembilan kecamatan di Kabupaten Minahasa Selatan yang mencapai kriteria efektif, empat kecamatan dengan kriteria cukup efektif, satu kecamatan dengan kriteria kurang efektif dan tiga kecamatan dengan kriteria tidak efektif.

\subsection{Pembahasan}

Strategi Penerimaan Pajak Bumi dan Bangunan Pedesaan dan Perkotaan Kabupaten Minahasa Selatan. Pada hasil penelitian tentang analisis strategi pada Kabupaten Minahasa Selatan dapat diuraikan bahwa dalam mekanisme strategi yang dilakukan terbagi menjadi tiga tahapan yaitu Perumusan, Pelaksanaan dan Penilaian Strategi Perumusan Strategi. Dalam tahap awal yaitu pada saat perumusan strategi. Pemerintah Kabupaten Minahasa Selatan menentukan sistem yang digunakan dalam pemungutan Pajak, yaitu Official Assessment System. Menurut Mardiasmo (2016: 9). Official Assessment System adalah suatu sistem yang memberi wewenang kepada pemerintah dalam (fiskus) untuk menentukan besarnya pajak terutang oleh wajib pajak. Penetapan besarnya pajak terutang ini berdasarkan tarif yang ditetapkan di kalikan dengan NJOP yang telah dikurangi dengan NJOPTKP. Oleh karena itu tiap-tiap wajib pajak memiliki jumlah pajak terutang yang berbeda. Selanjutnya pemerintah melakukan sosialisasi PBB Pedesaan dan Perkotaan kepada wajib pajak, sosialisasi tersebut bertujuan untuk membangkitkan kesadaran masyarakat akan pentingnya membayar pajak. Dengan meningkatnya kesadaran masyarakat tentang pengetahuan tentang pajak dan betapa pentingnya membayar pajak, diharapkan dapat meningkatkan pendapatan asli daerah, terlebih khusus di bidang penerimaan PBB Pedesaan dan Perkotaan.

Penerapan Strategi. Pembagian tugas dalam pemungutan juga sangat penting. Di mana dapat mempengaruhi efektivitas penerimaan PBB Pedesaan dan Perkotaan. Dalam hal ini SPPT yang telah dicetak BP2RD, dibagikan ke wajib pajak dengan alur BP2RD ke Kecamatan, Kecamatan ke Desa lalu ke wajib pajak. Pajak yang tellah dibayarkan kemudian disetorkan kepada BP2RD.

Penilaian Strategi. Berdasarkan hasil wawancara di atas. Penilaian dari strategi sendiri yang di terapkan oleh Pemerintah Kabupaten Minahasa Selatan, belum ada penilaian secara khusus yang mengkaji lebih dalam mengenai apakah strategi yang telah diterapkan sudah berjalan 
dengan baik atau belum. Dilihat dari hasil penelitian di atas mengenai penilaian strategi, BP2RD menggunakan cara dengan membandingkan tingkat penerimaan PBB Pedesaan dan Perkotaan dengan target penerimaan PBB Pedesaan dan Perkotaan.

Efektivitas Penerimaan Pajak Bumi dan Bangunan Pedesaan dan Perkotaan. Efektivitas PBB Pedesaan dan Perkotaan dihitung dengan cara membandingkan realisasi penerimaan PBB Pedesaan dan Perkotaan dengan Target yang telah ditetapkan. Berdasarkan perhitungan tersebut dapat dilihat tingkat efektivitas penerimaan PBB Pedesaan dan Perkotaan pada tabel 4.4. Pada tahun 2016 tingkat efektivitas penerimaannya adalah sebesar 79.92\% dengan kriteria kurang efektif. Sedangkan, pada tahun 2017 tingkat efektivitas penerimaannya adalah sebesar 79.16\% dengan kriteria kurang efektif. Walaupun dari tingkat efektivitas penerimaan PBB Pedesaan dan Perkotaan terlihat mengalami penurunan sebesar 0,76\%, tapi jika dilihat dari jumlah pendapatan yang diterima tahun 2017 mengalami peningkatan pendapatan. Karena jumlah penerimaan pajak PBB Pedesaan dan Perkotaan pada tahun 2017 adalah sebesar Rp. 2.144.306.251,00 sedangkan pada tahun 2016 penerimaan PBB Pedesaan dan Perkotaan adalah sebesar Rp. 1.960.789.284,00. Dalam skala kecamatan, Penerimaan PBB Pedesaan dan Perkotaan di tahun 2016 terdapat sembilan kecamatan di Kabupaten Minahasa Selatan telah mencapai kriteria efektif. Pada Tahun 2017 sendiri tidak terdapat peningkatan jumlah kecamatan yang mencapai kriteria efektif, terapat sembilan kecamatan yang mencapai kriteria efektif. Dalam dua tahun berjalan, terdapat perubahan kepada kecamatan yang mencapai tingkat efektivitas di atas $90 \%$ atau kriteria efektif yaitu Modoinding, Motoling Barat, Sinonsayang dan Tatapaan. Di mana Modoinding dan Motoling Barat mengalami peningkatan hingga dapat mencapai kriteria efektif, sedangkan untuk Sinonsayang dan Tatapaan tidak dapat mencapai kriteria efektif pada tahun 2017. Menurut wawancara yang dilakukan dengan Bapak Bani, prosedur yang dilaksanakan dalam pemungutan PBB Pedesaan dan Perkotaan sudah sesuai prosedur yang berlaku. Hanya saja yang menjadi kendala yang sering ditemui dalam pelaksanaan pemungutan PBB Pedesaan dan Perkotaan adalah pada tingkat pemahaman wajib pajak dan bahkan petugas pemungutan pajak sendiri. Adapun wajib pajak yang kurang paham dengan PBB Pedesaan dan Perkotaan sering lalai dalam melaksanakan kewajiban sebagai wajib pajak. Dan di beberapa desa dan kecamatan itu sendiri, petugas yang ditugaskan untuk pemungutan PBB Pedesaan dan perkotaan tidak hadir pada saat pendistribusian SPPT ke kecamatan. Sehingga mengakibatkan SPPT yang seharusnya diberikan kepada wajib pajak tidak diterima oleh wajib pajak itu sendiri.

\section{KESIMPULAN DAN SARAN}

\subsection{Kesimpulan}

Berdasarkan analisis dan pembahasan yang dilakukan terhadap strategi penerimaan dan efektivitas penerimaan PBB Pedesaan dan Perkotaan di atas, maka dapat disimpulkan bahwa:

1. Mekanisme dari strategi penerimaan PBB Pedesaan dan Perkotaan di Kabupaten Minahasa Selatan, pada tahun anggaran 2016 sampai dengan 2017 memiliki tiga tahap. Yaitu tahap pertama Perumusan strategi. Dalam perumusan strategi Pemerintah Kabupaten Minahasa Selatan menetapkan sistem pemungutan Official Assessment System, penetapan target penerimaan dan mensosialisasikan PBB Pedesaan dan Perkotaan. Tahap kedua penerapan strategi. SPPT yang telah dicetak BP2RD kemudian di distribusikan ke tiap-tiap kecamatan, dari kecamatan ke desa-desa dan terakhir ke wajib pajak yang di serahkan oleh kepala lingkungan wajib pajak tersebut. Tahap ketiga Penilaian Strategi. Pemerintah Kabupaten Minahasa Selatan melakukan penilaian strategi berdasarkan perbandingan penerimaan dan target yang telah ditetapkan. 
2. Pada tahun 2016 tingkat efektivitas penerimaan PBB Pedesaan dan Perkotaan adalah sebesar 79.92\% dengan kriteria kurang efektif. Dan pada tahun 2017 tingkat efektivitas penerimaan adalah sebesar 79.16\% dengan kriteria kurang efektif. Jadi dapat disimpulkan bahwa Efektivitas penerimaan Pajak Bumi dan Bangunan Pedesaan dan Perkotaan di Kabupaten Minahasa Selatan pada tahun 2016-2017 tergolong kurang efektif.

3. Pemungutan PBB Pedesaan dan Perkotaan, Pemerintah Kabupaten Minahasa Selatan terkendala oleh beberapa hal. Kendala yang paling berpengaruh adalah, kurangnya kesadaran dan pemahaman wajib bajak dalam membayar pajak. Kendala kedua adalah kurangnya pemahaman penagihan wajib pajak oleh petugas, yang mengakibatkan tidak tertagihnya PBB Pedesaan dan Perkotaan.

\subsection{Saran}

1. Pemerintah Kabupaten Minahasa selatan lebih baik menambahkan kriteria lain dalam penilaian strategi pemungutan Pajak Bumi dan Bangunan Pedesaan dan Perkotaan (PBB P2). Agar tahun-tahun ke depannya dapat lebih memperbaiki kekurangan yang dianggap perlu di perbaiki di tahun-tahun sebelumnya.

2. Untuk meningkatkan efektivitas penerimaan Pajak Bumi dan Bangunan Pedesaan dan Perkotaan (PBB P2), Pemerintah Kabupaten Minahasa Selatan dalam hal ini Badan Pengelola Pajak dan Retribusi Daerah (BP2RD), harus lebih lagi memberikan pemahaman mengenai PBB P2 kepada wajib pajak.

3. Badan Pengelola Pajak dan Retribusi Daerah (BP2RD) harus lebih banyak lagi memberikan pelatihan dan tambahan pengetahuan kepada petugas yang di tunjuk untuk melakukan penagihan kepada wajib pajak. Untuk menghindari kesalahan pada saat pendistribusian SPPT dan penagihan pajak.

\section{DAFTAR PUSTAKA}

David, F. R. 2011. Strategic Management, Buku 1. Edisi 12 Jakarta: Salemba Empat

Kuncoro. 2011. Metode Kuantitatif: Teori dan Aplikasi untuk Bisnis dan Ekonomi. Sekolah Tinggi Ilmu Manajemen YKPN.

Mahmudi, 2011. Analisis Laporan Keuangan Pemerintah Daerah. Sekolah tinggi Ilmu Manajemen. Jurnal Riset dan Akuntansi.

Mardiasmo 2016. Perpajakan Edisi Terbaru 2016. Yogyakarta: ANDI 2018. Perpajakan Edisi Terbaru 2018. Yogyakarta: ANDI

Prathiwi. Herawati, N. T. dan Sulindawati. 2015. Analisis Strategi Penerimaan Pajak Bumi dan Bangunan Pedesaan dan Perkotaan (PBB P2) Serta Efektivitas Penerimaannya di Pemerintah Kota Denpasar Tahun 2013-2014. Skripsi. Program Akuntansi S1. Universitas Pendidikan Ganesha.

Pudihang, S. Morasa, J. Dan Gamaliel, H. 2017. Mekanisme Pemungutan Pajak Atas Pemindahan Hak Pada Jual Beli Tanah Dan Bangunan Di Kabupaten Kepulauan Siau Tagulandang Biaro (Sitaro. Jurnal Riset Akuntansi Going Concern Vol. 12 No. 1. Universitas Sam Ratulangi.

Resmi, S. 2009. Perpajakan : Teori dan Kasus. Jakarta: Salemba Empat.

Satori, D dan Komariah, A. 2014. Metodologi Penelitian Kualitatif. Bandung: Alfabeta

Sugiyono. 2012. Metode Penelitian Kuantitatif dan Kualitatif dan R\&D. Bandung: Alfabet.

Suhartono, R. dan Ilyas, W.B . 2010. Ketentuan Umum dan Tata Cara Perpajakan (KUP). Jakarta. Salemba Empat.

Undang-Undang Republik Indonesia Nomor 16 Tahun 2009. Perubahan Keempat atas Undang-Undang Nomor 06 Tahun 1983 Tentang Ketentuan dan Tata Cara 
Perpajakan Menjadi Undang-Undang. 25 Maret 2009. Lembaran Negara Republik Indonesia Tahun 2009 Nomor 62. Jakarta.

Undang-Undang Republik Indonesia Nomor 28 Tahun 2009. Pajak Daerah dan Retribusi Daerah. 15 September 2009. Lembaran Negara Republik Indonesia Tahun 2009 Nomor 130. Jakarta 